\title{
Air gasification of empty fruit bunch for hydrogen-rich gas production in a fluidized- bed reactor
}

\begin{abstract}
A study on gasification of empty fruit bunch (EFB), a waste of the palm oil industry, was investigated. The composition and particle size distribution of feedstock were determined and the thermal degradation behaviour was analysed by a thermogravimetric analysis (TGA). Then fluidized bed bench scale gasification unit was used to investigate the effect of the operating parameters on EFB air gasification namely reactor temperature in the range of $700 \ddot{1}$ $1000{ }^{\circ} \mathrm{C}$, feedstock particle size in the range of $0.3 \mathrm{i} 1.0 \mathrm{~mm}$ and equivalence ratio (ER) in the range of $0.15 \mathrm{i} 0.35$. The main gas species generated, as identified by a gas chromatography (GC), were $\mathrm{H} 2, \mathrm{CO}, \mathrm{CO} 2$ and $\mathrm{CH} 4$. With temperature increasing from $700{ }^{\circ} \mathrm{C}$ to $1000{ }^{\circ} \mathrm{C}$, the total gas yield was enhanced greatly and reached the maximum value ( $\sim 92 \mathrm{wt} \%$, on the raw biomass sample basis) at $1000{ }^{\circ} \mathrm{C}$ with big portions of $\mathrm{H} 2$ (38.02 vol.\%) and $\mathrm{CO}(36.36$ vol.\%). Feedstock particle size showed an influence on the upgrading of $\mathrm{H} 2, \mathrm{CO}$ and $\mathrm{CH} 4$ yields. The feedstock particle size of $0.3 \mathrm{i} 0.5 \mathrm{~mm}$, was found to obtain a higher $\mathrm{H} 2$ yield (33.93 vol.\%), and higher LHV of gas product $(15.26 \mathrm{MJ} / \mathrm{m} 3)$. Equivalence ratio (ER) showed a significant influence on the upgrading of hydrogen production and product distribution. The optimum ER (0.25) was found to attain a higher $\mathrm{H} 2$ yield (27.31 vol.\%) at $850{ }^{\circ} \mathrm{C}$. Due to the low efficiency of bench scale gasification unit the system needs to be scaling-up. The cost analysis for scale-up EFB gasification unit showed that the hydrogen supply cost is RM 6.70/kg EFB $(\$ 2.11 / \mathrm{kg}=\$ 0.18 / \mathrm{Nm} 3)$.
\end{abstract}

Keyword: Biomass; Empty fruit bunch; Gasification; Hydrogen; Yield; Energy source 